\title{
NUMERICAL ANALYSIS OF CAVITATION INSTABILITIES IN INDUCER BLADE CASCADE
}

\author{
Benoît Pouffary \\ Centre National d'Etudes Spatiales \\ Evry - France
}

\author{
Regiane Fortes Patella \\ INPG - LEGI \\ Grenoble - France
}

\author{
Jean-Luc Reboud \\ CNRS-LEMD, University of \\ Grenoble - France
}

\begin{abstract}
The cavitation behavior of a four-blade rocket engine turbopump inducer was simulated by the CFD code Fine/Turbo ${ }^{\mathrm{TM}}$. The code was modified to take into account a cavitation model based on a homogeneous approach of cavitation, coupled with a barotropic state law for the liquid/vapor mixture [1-4]. In the present study, the numerical model of unsteady cavitation was applied to a four-blade cascade drawn from the inducer geometry.

Unsteady behavior of cavitation sheets attached to the inducer blade suction side depends on the flow rate and cavitation number $\sigma$. Numerical simulations of the transient evolution of cavitation on the blade cascade were performed for nominal flow rate and different cavitation numbers, taking into account simultaneously the four blade-to-blade channels. Depending on the flow parameters, steady or unsteady behaviors spontaneously take place. In unsteady cases, sub synchronous or super synchronous regimes were observed. Some mechanisms responsible for the development of these instabilities are proposed and discussed.
\end{abstract}

\section{INTRODUCTION}

One of the most prejudicial consequences of the cavitation in the rocket engine turbopump inducers is the generation of system and machinery instabilities. Machinery instabilities may appear for particular range of the cavitation number, near to the performance drop. These unsteady phenomena are associated to different rotating non-symmetrical cavitation patterns, which are characterized by sub or super synchronous frequencies.

Cavitation instabilities lead to downstream and upstream pressure fluctuations, which may be at the origin of system instabilities. They induce also axial and radial forces on the blades and shaft, which can disturb the bearings working and endanger the turbopump running.

For these reasons, inducer cavitation instabilities have been studied for many years in the aim of observing, better understanding, quantifying, and predicting such phenomena. Several experimental works, performed by [5-9], allowed to the visualization of global cavitation patterns and to the measurement of the radial loads on the shaft due to cavitation instabilities.

More recently, theoretical and numerical models have been developed to predict these instabilities and to analyze their origin [10-15].

Through collaborations between the laboratory LEGILaboratoire des Ecoulements Géophysiques et Industriels, the Rocket Engine Division of SNECMA Moteurs, the French Space Agency CNES, and NUMECA International, a cavitation physical model was implemented in the commercial code Fine/Turbo ${ }^{\mathrm{TM}}$. The code allows steady and unsteady cavitating flows calculations in 2D or 3D geometries, as presented in [13], and it can be used as a tool to analyze inducer instabilities.

In this context, the main target of the present study is to present some numerical results obtained in a blade cascade. The work illustrates the sub synchronous and super synchronous cavitation regimes observed, and propose the qualitative analyses of mechanisms responsible for these instabilities.

\section{NOMENCLATURE}

$$
\begin{array}{ll}
\mathrm{A}_{\min }: \mathrm{A}_{\min }{ }^{2}=\left[\left(\rho_{\mathrm{l}}-\rho_{\mathrm{v}}\right) / 2\right] \mathrm{c}_{\min }{ }^{2} & (\mathrm{~m} / \mathrm{s}) \\
\mathrm{C}_{\min }: \text { minimum sound speed in the medium } & (\mathrm{m} / \mathrm{s}) \\
\mathrm{P}: \text { local static pressure } & (\mathrm{Pa}) \\
\mathrm{P}_{\text {ref }}: \text { reference pressure } & (\mathrm{Pa}) \\
\mathrm{P}_{\mathrm{v}}: \text { vapor pressure } & (\mathrm{Pa}) \\
\mathrm{R}_{\mathrm{c}}: \text { cut radius for the passage from 3D to } 2 \mathrm{D} & (\mathrm{m}) \\
\mathrm{T}_{0}: \text { inducer rotation period } & (\mathrm{s}) \\
\mathrm{T}_{\text {ref }}: \text { reference time = blade passage time }=\mathrm{T}_{0} / 4 & (\mathrm{~s}) \\
\mathrm{V}_{\text {ref }}: \text { reference velocity }\left(=\mathrm{R}_{\mathrm{c}} \Omega\right) & \left(\mathrm{ms}^{-1}\right) \\
\alpha: \text { void ratio } & - \\
\Omega: \text { angular rotation speed of the inducer } & \left(\mathrm{rd}^{-1} \mathrm{~s}^{-1}\right) \\
\rho: \text { mixture density } & \left(\mathrm{kg} / \mathrm{m}^{3}\right) \\
\rho_{\mathrm{l}\left(=\rho_{\text {ref }}\right), \rho_{\mathrm{v}}: \text { liquid }(=\text { ref }), \text { vapor density }} & \left(\mathrm{kg} / \mathrm{m}^{3}\right) \\
\sigma:\left(\mathrm{P}_{\text {ref }}-\mathrm{P}_{\mathrm{v}}\right) /\left(\rho \mathrm{V}_{\text {ref }} / 2\right) \text { cavitation number } & - \\
\psi: \text { static pressure coefficient }=\left(\mathrm{P}-\mathrm{P}_{\text {ref }} /\left(\rho_{\mathrm{L}} \mathrm{V}_{\text {ref }} / 2\right)\right. & - \\
\Delta \mathrm{P}_{\text {tot }}: \text { total pressure variation in a channel } & \\
\multicolumn{1}{c}{\Delta \mathrm{P}_{\text {tot }}=\mathrm{P}_{\text {downstream }}-\mathrm{P}_{\text {upstream }}} & (\mathrm{Pa})
\end{array}
$$




\section{MODELS}

The applied numerical code solves the conservative unsteady RANS equations of a homogeneous fluid $[1,4]$. In the present study, the Spalart-Allmaras model was used to simulate turbulent behavior [16].

Associated to these basic equations, the barotropic state law proposed by [24] was implemented in the code to model mass transfer in cavitating flows. This simple model involves in the hypotheses of instantaneous vaporization and condensation phenomena, as well as the no-slip condition between liquid and vapor phases. It does not take into account thermal effects; i.e., the energy equation is not considered in the calculation. The liquid-vapor mixture is characterized by a mixture specific mass $\rho$ given as a function of void ratio $\alpha$, by the relation:

$$
\rho=\alpha \rho_{v}+(1-\alpha) \rho_{1}
$$

This barotropic law depends on the parameter " $\mathrm{A}_{\min }$ " (that is related to the minimum speed of sound in the mixture) and on the value of the density ratio $" \rho_{\mathrm{v}} / \rho_{\mathrm{l}}$ ", as illustrated by Figures 1 and 2.

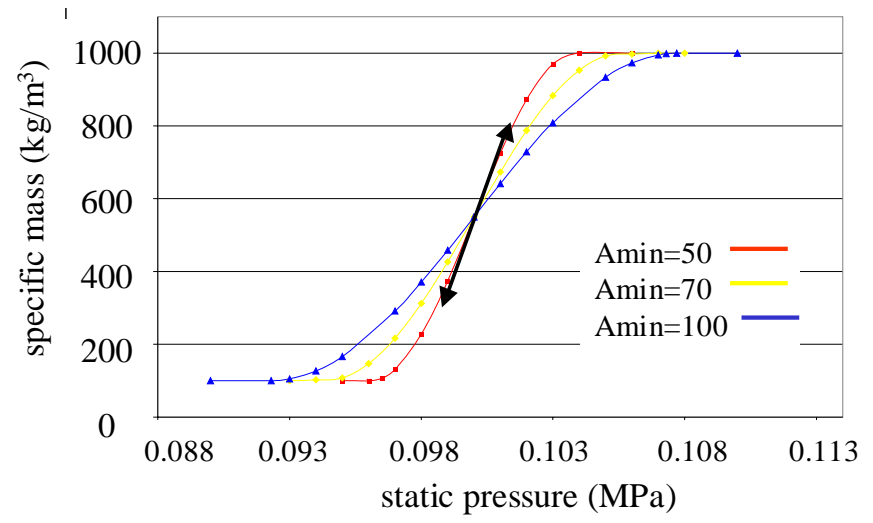

Figure 1: Scheme of the barotropic state law $\rho=\rho(P)$ Illustration of the parameter $A_{\min }$ influence.

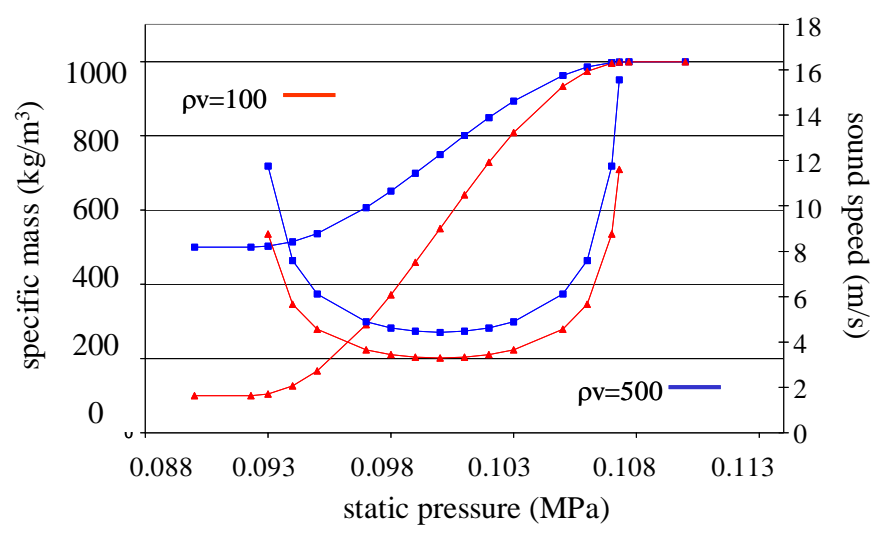

Figure 2: Illustration of the $\rho_{\mathrm{v}}$ influence on the barotropic law $\rho=\rho(P)$ and on the sound speed distribution $\left(A_{\min }=70 \mathrm{~m} / \mathrm{s}\right)$.

In the present study, the value of the minimum speed of sound $c_{\min }$ is taken equal to $4.7 \mathrm{~m} / \mathrm{s}\left(A_{\min }=100 \mathrm{~m} / \mathrm{s}\right)$ which is a little higher than the values used in our numerical previous works concerning cavitating flows in a Venturi apparatus [17]. The density ratio $\rho_{v} / \rho_{1}$ is imposed to be 0.1 . These choices were made to improve the robustness of these first feasibility computations with Fine/Turbo ${ }^{\mathrm{TM}}$ code. Further work is needed to better evaluate the influence of these parameters on the unsteady behavior of cavitating flows.

Regardless of considered hypotheses, previous studies [17-20] pointed out that the barotropic approach can succeed to quantitative and qualitative prediction of cavitating flows global parameters (i.e. characteristic frequencies, vapor structures size, pump performance) as well as mean local parameters (void ratio and velocity distribution).

These physical models have been implemented in the code Fine/Turbo ${ }^{\mathrm{TM}}$ developed by NUMECA International. It is a three-dimensional structured mesh code that solves the time dependant Reynolds-averaged Navier-Stokes equations. Time accurate resolutions use the dual time stepping approach proposed by Jameson [21]. Pseudo-time derivative terms are added to the equations. They march the solution towards convergence at each physical time step.

This kind of resolution is devoted to highly compressible flows. In the case of low-compressible or incompressible flows, its efficiency decreases dramatically. This well-known problem has been addressed by many authors and solved by introducing a preconditioner [4]. This one is based on the studies presented in [22-23], and has been modified to take into account the cavitation model.

The discretization is based on a finite volume approach. We use a second order central scheme that must be associated with two artificial dissipation terms, respectively of second and fourth order. The first one is activated in the strong pressure and density gradient areas. The other one is used in the whole domain, and it results in a second order space accuracy. The pseudo-time integration is made by a four-step Runge-Kutta procedure.

The physical time-derivative terms are discretized with a second order backward difference scheme that ensures a second order accuracy in time.

A meaningful numerical work has been performed recently by [2] to improve the preconditioner and the stability of numerical code for calculations of cavitating flows. A more detailed description of the code is given in [3,4].

\section{GEOMETRY AND MESH}

An example of studied inducer geometry is given in Figure 3. Because of prohibitive calculation time for unsteady flows in 3D inducer geometry, a 2D approached geometry was adopted.

As a matter of fact, in the range of running conditions, the angle of attack remains very small for the considered inducer geometry. In these conditions, the inlet back-flow is not relevant and a 2D geometry approach can be used for qualitative analyses.

Hence, computations are performed in a four-blade cascade representing an entire inducer. The transformation from the 3D geometry to the 2D blade cascade leads to neglect the peripheral cavitation in the inducer: only cavitation sheets attached on the blades will be considered. To obtain the 2D geometry, the $3 \mathrm{D}$ inducer (Figure 3 ) is cut at a constant radius $\mathrm{R}_{\mathrm{c}}$ equal to $70 \%$ of the tip radius $\mathrm{R}$.

We use a 215x31 structured mesh per blade-to-blade channel, giving a total of 26660 internal nodes when calculating the four-blade cascade. The boundary conditions are: imposed velocity at the mesh inlet, imposed static pressure at the outlet, and periodicity or connection conditions between the different channels of the blade cascade (Figure 4). 
The time step, mesh and turbulence model are chosen to put the attention on the low frequency fluctuations of the attached cavity, more than to the local unsteadiness in the cavitation sheet wake (cloud shedding).

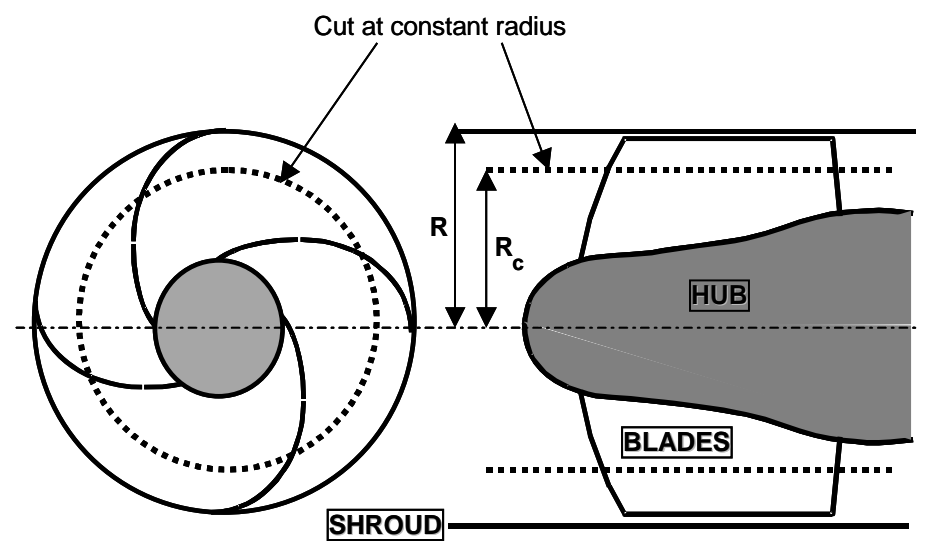

Figure 3: Inducer 3D geometry - frontal and meridian planes

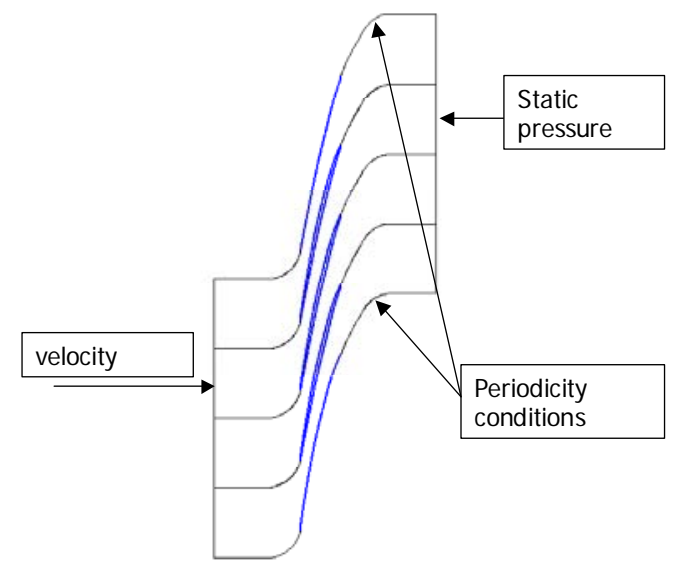

Figure 4: Blade cascade corresponding to the cut at constant radius of the $3 \mathrm{D}$ inducer geometry.

\section{QUALITATIVE RESULTS}

Several four-channel computations are performed at nominal flow rate, for different cavitation number $\sigma$ (based on outlet reference pressure) varying from low cavitating conditions down to the final performance drop of the cascade. The corresponding head drop chart is drawn in Figure 5 at nominal flow rate.

Stable configurations correspond to cavitation numbers lower than 0.65 or higher than 0.8 (square dots in the figure). For $\sigma>0.8$, cavitation sheets are small and identical on the 4 blades. For these flow conditions, the performance of the runner is only slightly affected by the presence of vapor. For $\sigma$ $<0.65$, the cavitation sheets are much more developed, and they are responsible for the important performance drop observed. The performance drop of the cascade is directly related to the evolution of the blade load illustrated by Figure 6: the appearance of cavitation structures at the pressure side of the blade leads to the decrease of the applied mechanical torque, and consequently to the performance drop.

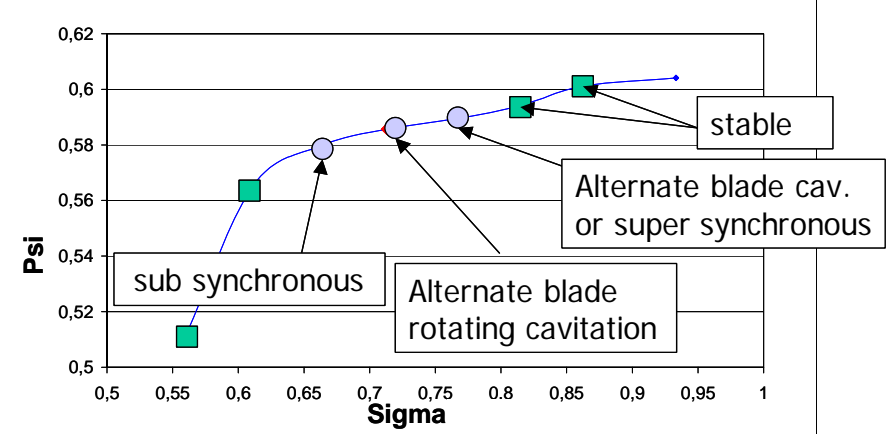

Figure 5: Performance chart at nominal flow rate

Static pressure coefficient $\psi$ vs $\sigma_{\text {downstream }}$

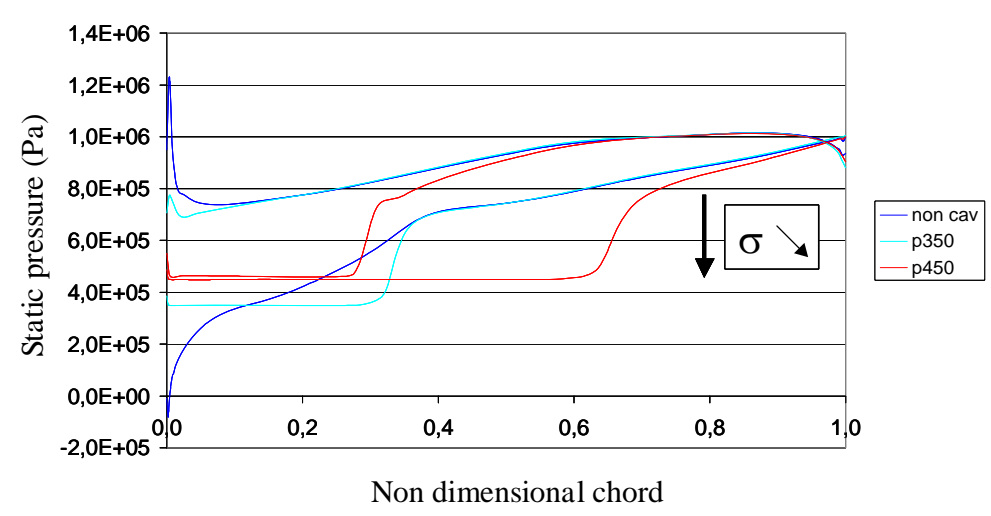

Figure 6: Mean static load of the blade at mid span for three different cavitation numbers $\sigma_{\text {dowstream. }}$

Circular dots in Figure 5 correspond to unsteady regimes and define the range of cavitation instabilities of the cascade. Three kinds of instabilities have been observed from our calculations: a super synchronous behavior, a sub synchronous configuration and a rotating alternate blade cavitation.

Calculations are done in relative referential: sub or super synchronous configurations are determined by the unsteady visualization of the cavitation sheets. For example, if the non symmetrical cavitation sheet pattern rotates in the same direction as the inducer, the characteristic frequency of the instability is added to the inducer rotation frequency and a super synchronous configuration is established. In another way, sub synchronous regimes are characterized by cavitation patterns that rotate in the opposite direction as the inducer.

\section{Alternate blade cavitation}

For $\sigma_{\text {downstream }} \sim 0.75$, two kinds of cavitation configurations have been observed. The first one is the alternate blade cavitation (Figure 7). The system here is symmetrical, characterized by two radial opposite large vapor sheets and two opposite small ones.

For this cavitation number, the calculations pointed out also the appearance of another cavitation configuration, associated to a super synchronous behavior.

\section{Super synchronous configuration}

Figure 8 illustrates this kind of instability. It is characterized by a non-symmetrical rotating pattern of vapor sheets: we observe four different sizes of cavitation sheets in the four channels. 


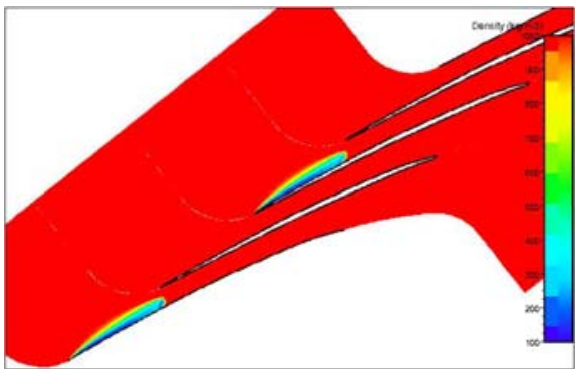

Figure 7: Alternate blade cavitation ( $\sigma \sim 0.75)$ Density fields calculated in the blade cascade.
Calculations indicate that this cavitation pattern rotates in the blade cascade in the same direction as the inducer rotation, but more quickly.

\section{Rotating alternate blade cavitation}

For $\sigma_{\text {downstream }} \sim 0.7$, another type of alternate blade configuration has been observed. As illustrated by Figure 9, for this cavitation number, the cavitation pattern is initially characterized by two opposite large sheets in channel 1 and 3, separated by two channels without cavitation. During two periods of inducer rotation, this configuration shifts and the large vapor structures change to channels 2 and 4 .

This kind of configuration was studied in a previous work presented in [14].
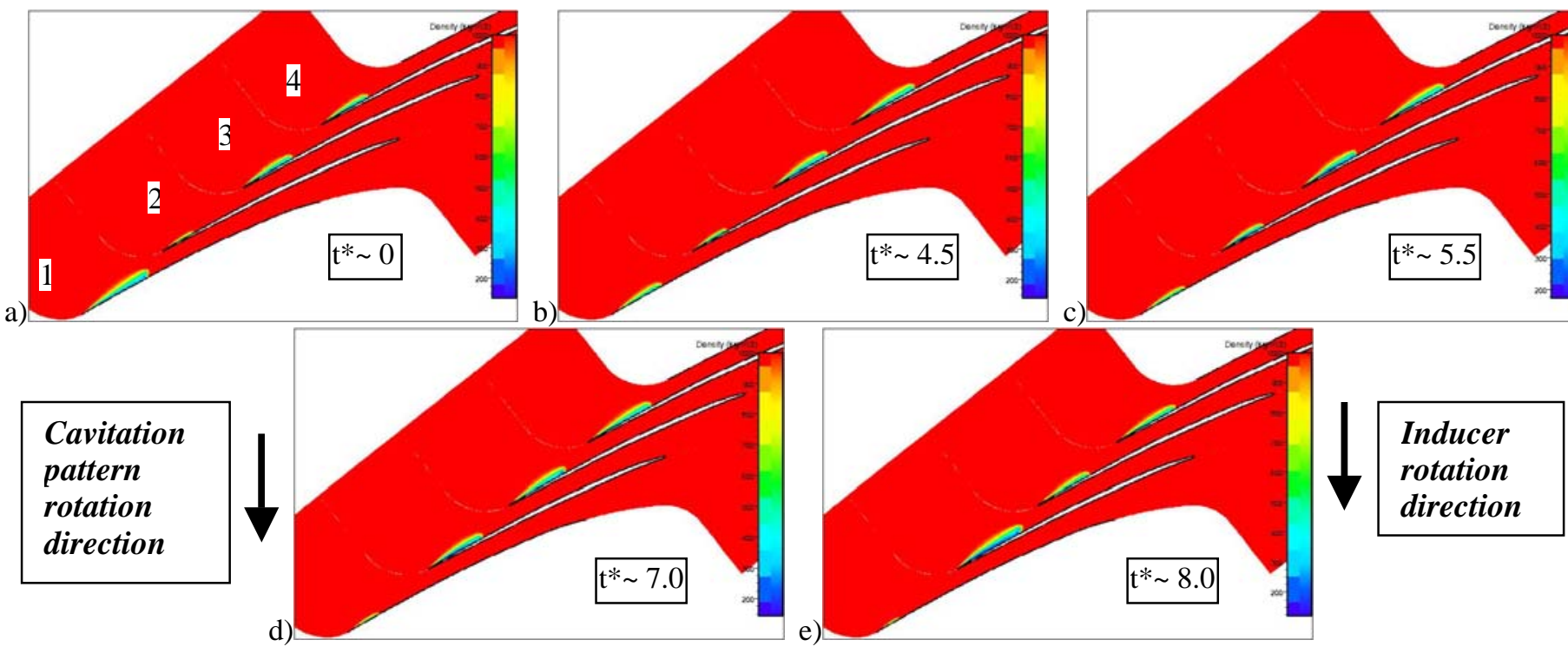

Figure 8: Visualization, in the case of super synchronous configuration, of the vapor structures (density fields) at five different times during a complete inducer rotation period.

a)
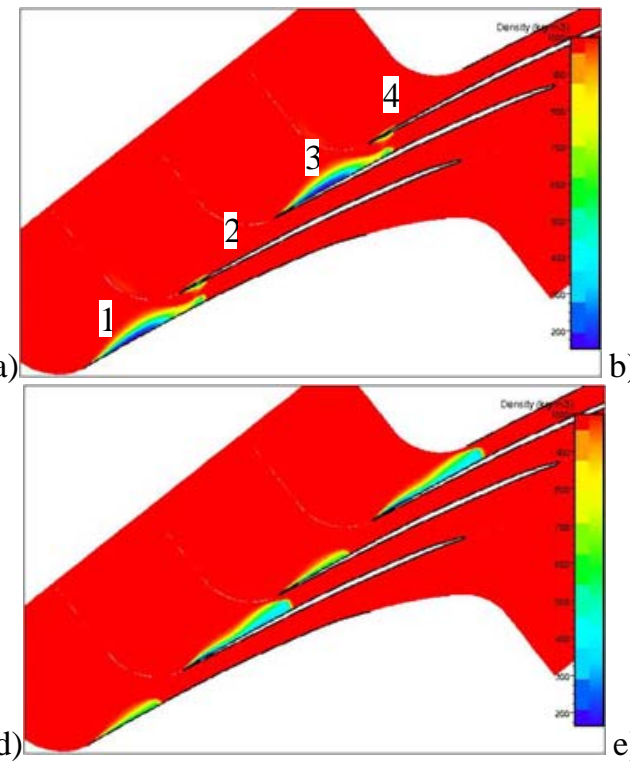
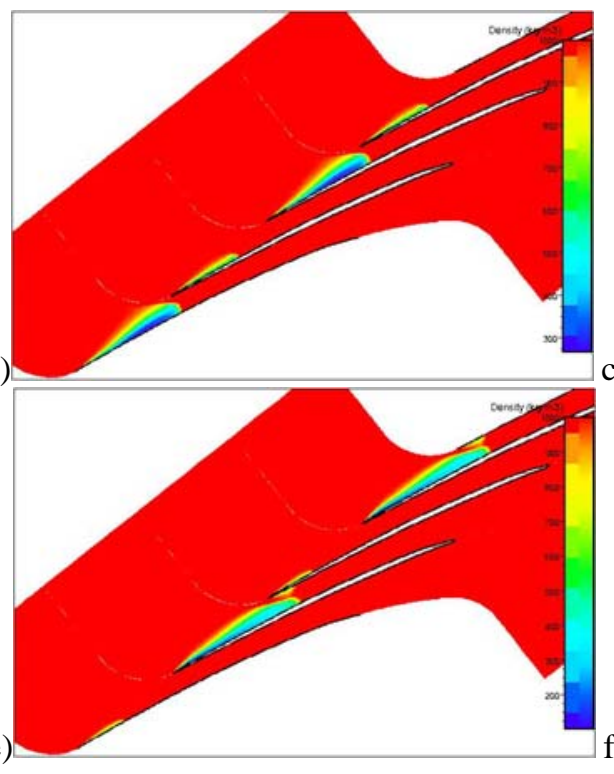

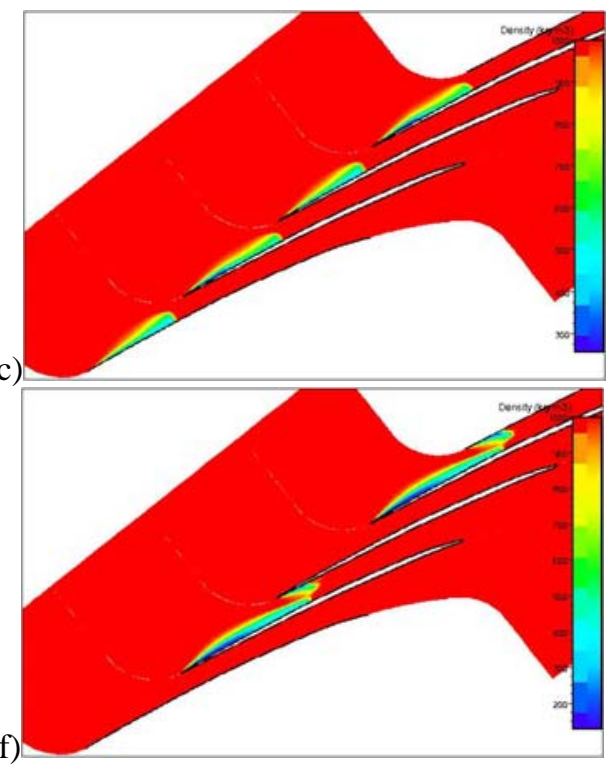

Figure 9: Rotating alternate blade configuration: figures illustrate density fields at six different times during approximately two inducer rotation periods. 


\section{Sub synchronous configuration}

For smaller cavitation numbers ( 0.65), a sub synchronous configuration appears (Figure 10). In this case, the cavitation pattern is not symmetrical: we observe four sheets of different sizes. The largest sheet occurring in the channel 3 obstructs the flow in this channel and leads to the increase of the cavitation sheet in the upper channel. This configuration rotates in the opposite direction as the inducer rotation.

\section{FLOW QUALITATIVE ANALYSES}

Based on the results presented here above, we propose in this paper a qualitative analysis of the mechanisms responsible for the instabilities phenomena observed.

\section{Sub synchronous configuration}

According to our calculations, and by making an analogy with rotating stall phenomenon observed in compressor inlet, the sub synchronous configuration seems to be associated with the obstruction of a channel by the largest sheet, as schematized in Figure 11. This obstruction deviates the flow and modifies the angle of attack of the neighboring upper channel, which leads to a pressure decrease and to the increase of the cavitation sheet size in this channel. Otherwise, as flow rate is imposed as a constant in the inducer, the flow angle of attack in the channel below the obstructed channel should decrease, which leads to the reduction of vapor structure size in this channel.

Hence, this kind of rotating cavitation configuration would be strongly coupled with the modification of the angle of attack due to the flow rate fluctuations in the channels.

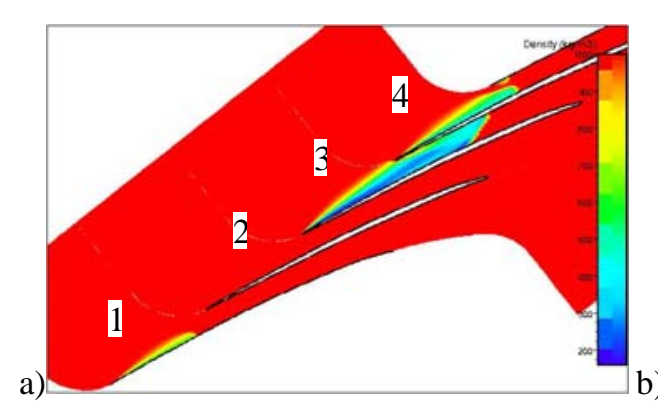

a)

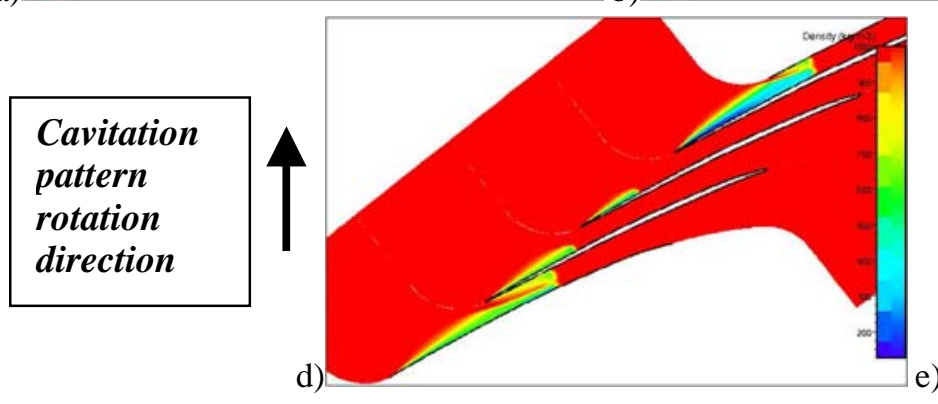

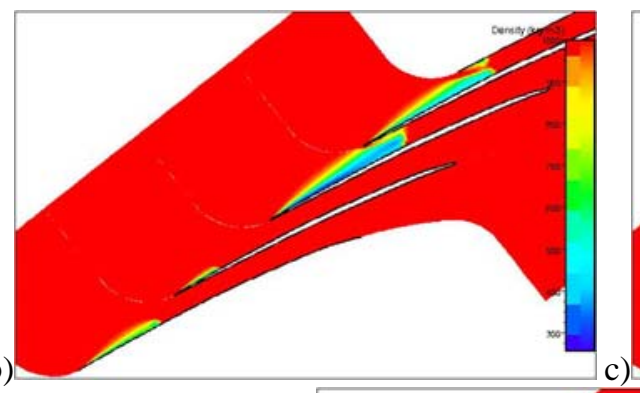
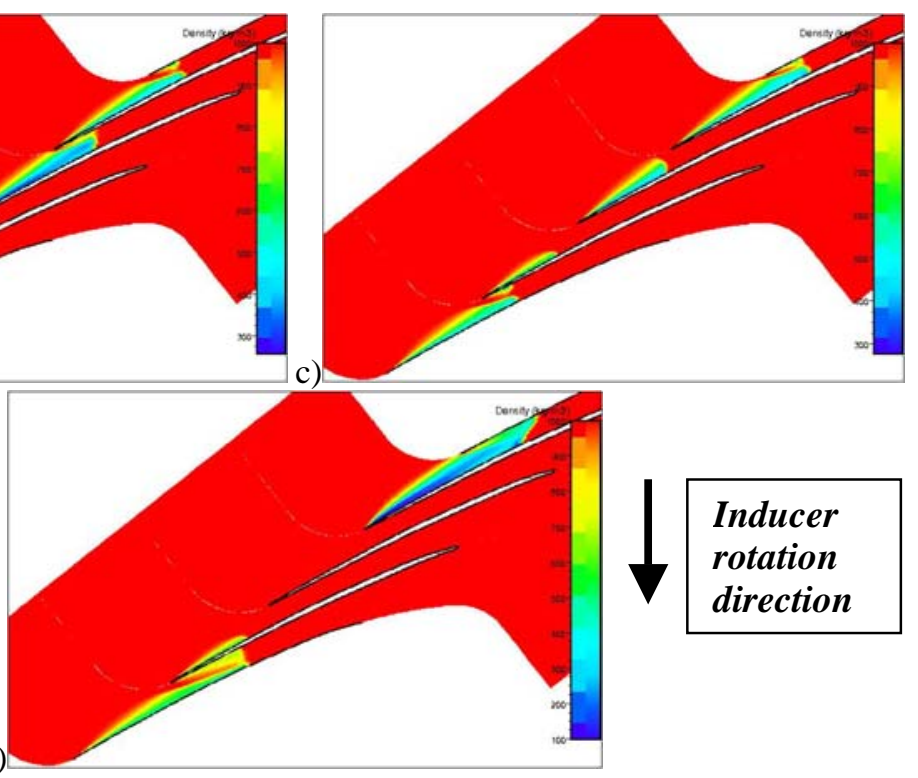

Figure 10: Visualization, in the case of sub synchronous configuration, of the vapor structures (density fields) at five different times during a complete inducer rotation period.
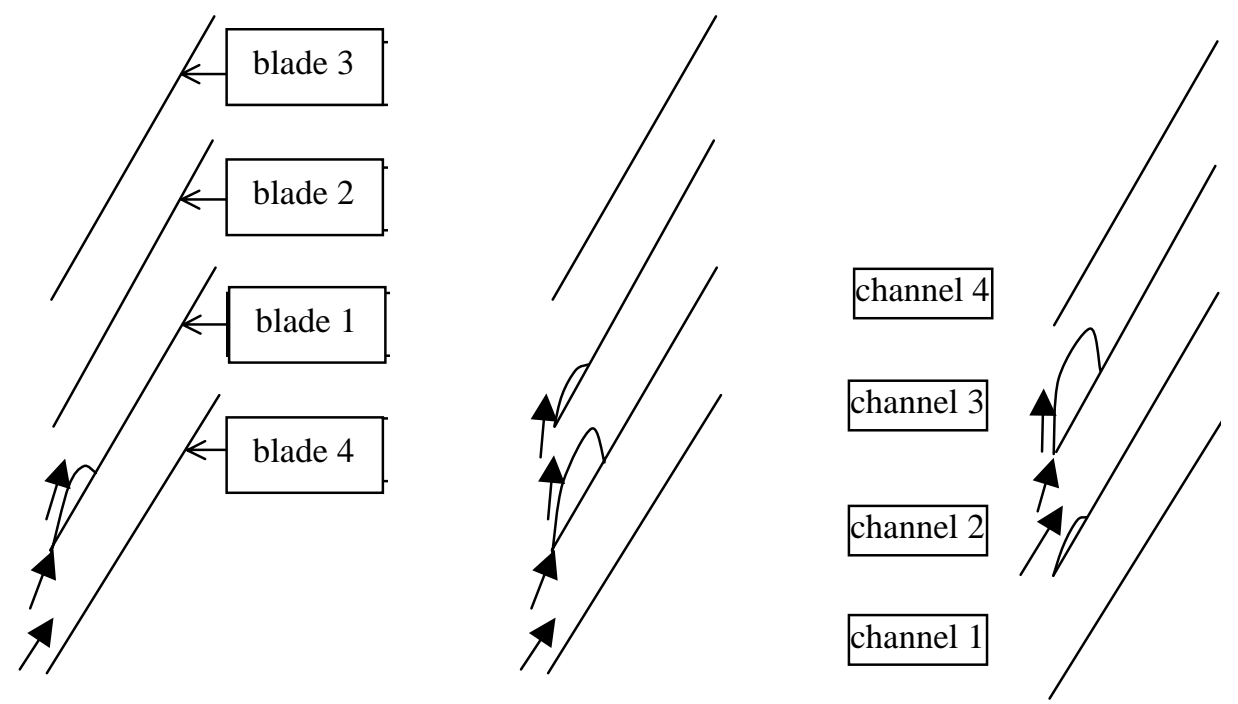

Figure 11: Illustration of the propagation of the largest sheet in the case of sub synchronous configuration 


\section{Super synchronous configuration}

To identify and analyze the mechanism responsible for the super synchronous instabilities, we will adopt the nomenclature introduced in the Figure 11.

Firstly, we will study the time evolution of the inlet and outlet flow rates in each channel during an inducer rotation period (Figure 12), as well as the corresponding transient evolution of the total pressure variation $\Delta \mathrm{P}_{\text {tot }}$ (Figure 13). The difference between outlet and inlet flow rates in a channel (figure 12) represents the variation of volume of the vapor structure in the channel. These results concern the unsteady cavitation pattern illustrated in Figure 8.

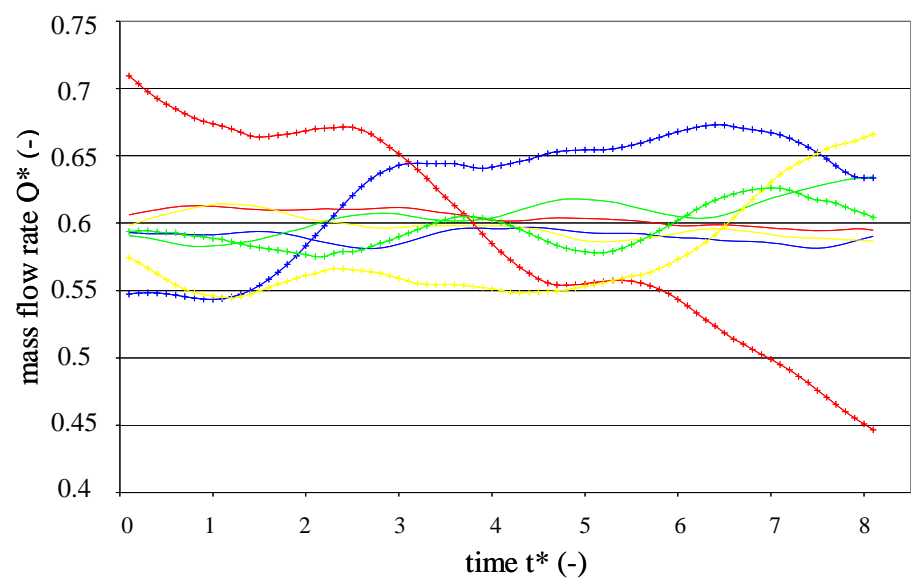

Figure 12: Time evolution of the non-dimensional mass flow rate in the four channels ( $\sigma=0.75$; super synchronous configuration). Full and doted lines represent, respectively, outlet and inlet flow rates in channel 1 (blue), channel 2 (red), channel 3 (yellow) and channel 4 (green).

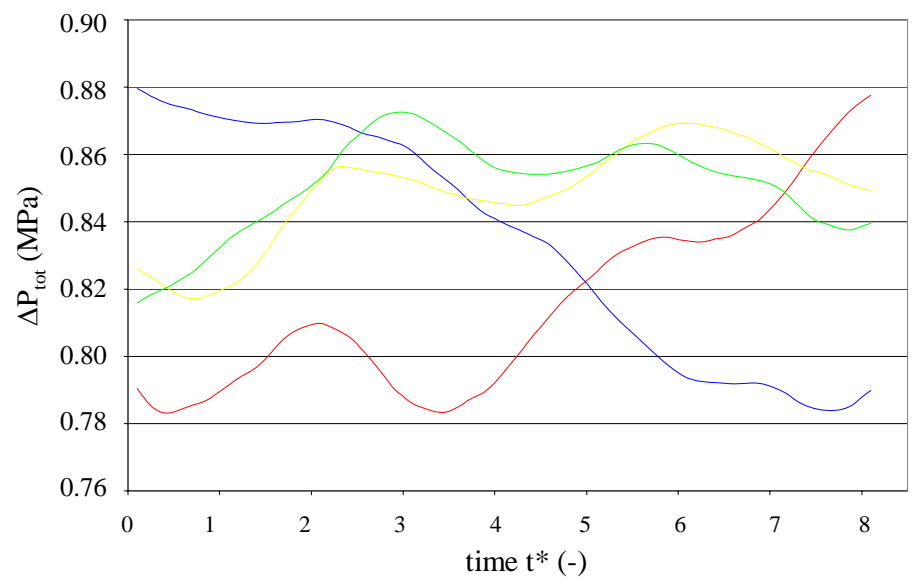

Figure 13: Time evolution of the total pressure variation $\Delta \mathrm{P}_{\text {tot }}$ for each channel. $\Delta \mathrm{P}_{\text {tot }}=\mathrm{P}_{\text {downstream }}-\mathrm{P}_{\text {upstream }}$.

Channel 1 (blue), 2 (red), 3 (yellow) and 4 (green).

These results point out that:

- the rise of the cavitation sheet size in channel 2 (between blades 1 and 2) leads to a partial obstruction of this channel, which induces the mass flow rate decrease.

- as a consequence of the cavity length increase, we can observe the augmentation of total pressure variation in the channel 2. As a matter of fact, the cavitation sheet on blade 1 does not reach the channel throat (i.e., the channel is not completely obstructed). The $\Delta \mathrm{P}_{\text {tot }}$ (or blade load) increase is due to the rise of the angle of attack at the blade 1 , which is associated with the flow rate decrease in channel 2 .

- during the rotation of the small sheet from channel 2 to channel 1 , the flow rates and $\Delta \mathrm{P}_{\text {tot }}$ in channels 3 and 4 are slightly modified.

Contrarily to the sub synchronous configuration, the propagation of the super synchronous instability seems not to be related only to the inlet flow velocity fields. Indeed, the instability moves in the opposite direction as the velocity fields, as schematized by Figure 14 .

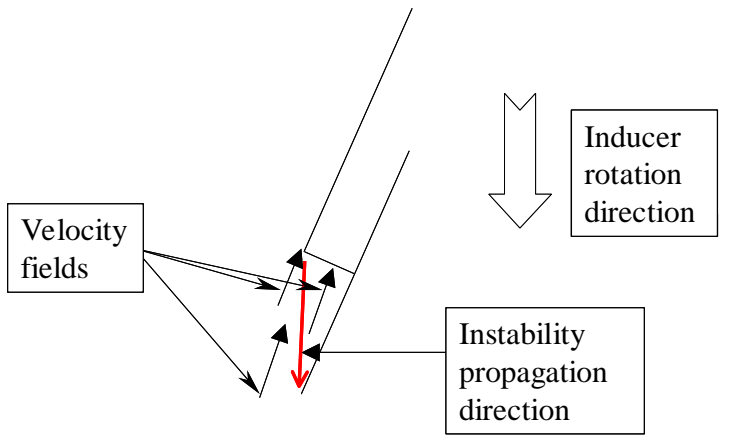

Figure 14: Scheme of the flow velocity, instability propagation and inducer rotation directions.

Hence, we think that the mechanism responsible for this kind of instability should be related mainly to the pressure field in the blade cascade. To study pressure fields, Figures 15 illustrate the time evolution of the blade loads during the propagation of super synchronous instability for a complete inducer rotation period (corresponding to Figure 8).

In agreement with the flow rates and $\Delta \mathrm{P}_{\text {tot }}$ time evolution analyses, we note that the loads of the blades 2 and 3 are slightly modified. Concerning blade 2 (Figure 15a), the pressure along the blade pressure side decreases during the development of the cavitation sheet in the channel 2. The load of the blade 3 (Figure 15b) is slightly modified at the blade suction side (probably due to the decrease of the cavitation sheet in the channel 1).

The loads concerning blades 1 (Figure 15c) and 4 (Figure 15d) are strongly modified by the cavitation instability. The increase of the vapor sheet length at the suction side of the blade 1 is associated with a strong pressure rise, on the pressure side, near to the leading edge. This peak pressure could be the mechanism responsible for the decrease of the sheet in channel 1.

To summarize, from the analyses of the whole of these unsteady results, we can propose the following scenario to explaining the cavitation super synchronous configuration (Figures 8 and 16):

- the growth of the cavitation sheet on the blade 1 suction side leads to the increase of the angle of attack on this blade.

- a consequence of this phenomenon is the rise of the pressure at the blade 1 pressure side, near the leading edge.

- the pressure field in the channel 1 , located below the blade 1 , is modified by this pressure rise, which leads to the decrease of the cavitation sheet attached to the blade 4 . 
- the presence of the cavitation sheet in the channel 4 will change the blade 4 angle of attack, inducing the progressive rise of the attached sheet cavitation, and the continuation of the instability propagation.
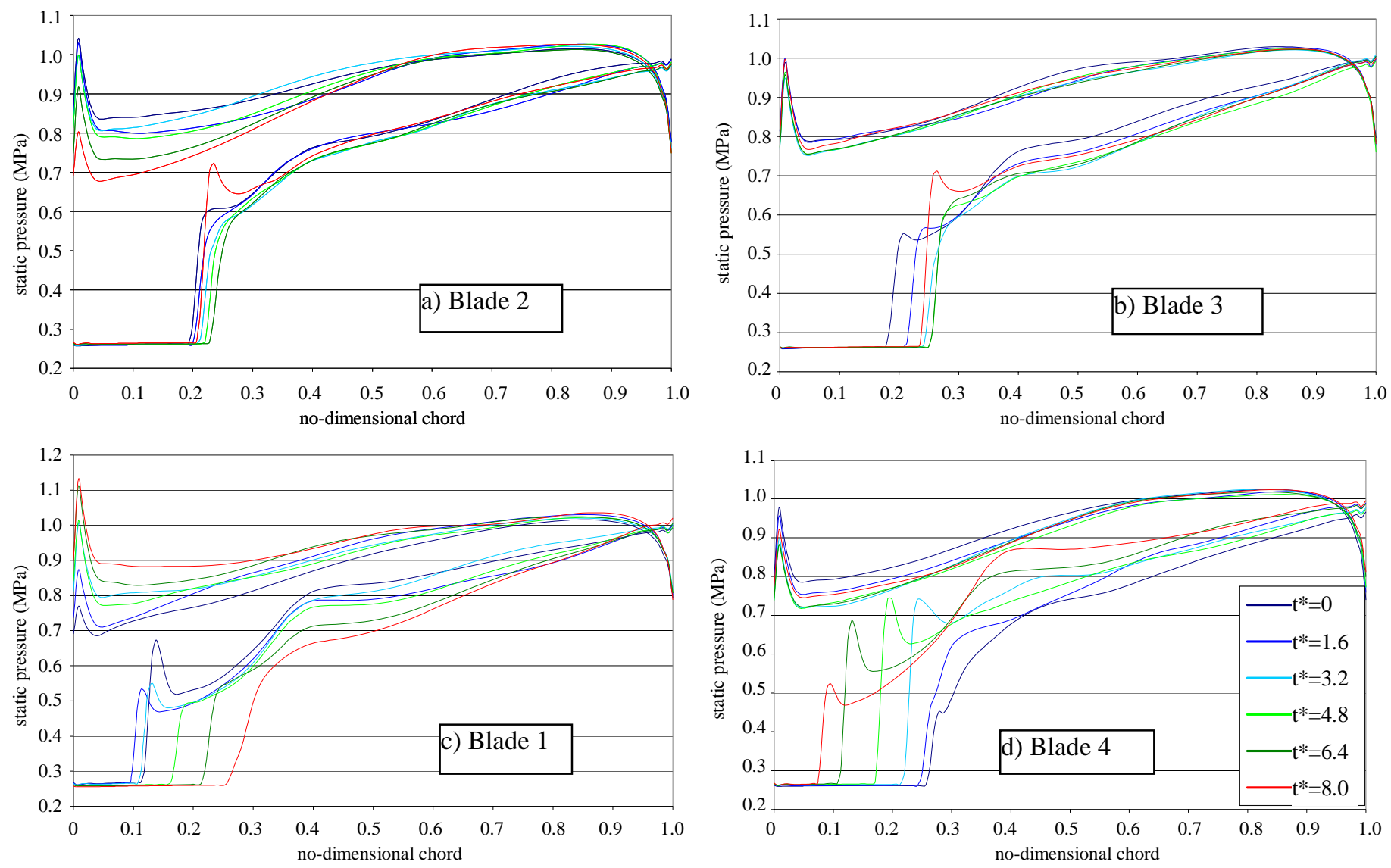

Figures 15: Time evolution of the blade loads in the super synchronous configuration.

(Increasing time from dark blue to red curves)

\section{CONCLUSION}

The Laboratory LEGI, in collaboration with the French space agency (CNES) and the rocket engine division of the SNECMA-Moteurs, develops for many years numerical codes to simulate and analyze cavitation phenomena, mainly occurring in turbopump inducer geometries. In the scope of a collaboration with NUMECA International, a cavitation model was implemented in the commercial code Fine/Turbo ${ }^{\mathrm{TM}}$. It has been applied successfully to perform calculations of 3D steady cavitating flows [3], as well as unsteady 2D simulations of cavitating flows.

In this paper, we presented first results obtaining by $2 \mathrm{D}$ unsteady calculation in a four-blade cascade drawn from an inducer geometry. Computations were performed at nominal flow rate for several cavitation numbers. The resulting performance chart was presented. A good agreement was found with previous work performed for the same geometry, by using another numerical code based on a different numerical scheme [14].

From presented calculations, five different cavitation patterns were observed:

- symmetrical stable configurations (for $\sigma<0.65$ or $>0.8$ ) characterized by four identical cavitation sheets;

- stable alternate blade cavitation (for $\sigma \sim 0.75$ );
- super synchronous configuration (also for $\sigma \sim 0.75$ by intermittency);

- rotating alternate blade cavitation (for $\sigma \sim 0.7$ );

- and sub synchronous configuration (for $\sigma \sim 0.65$ ).

Based on the qualitative analyses of numerical results (i.e.: density, velocity, pressure fields; time evolution of the mass flow rates and of the blade loads), the mechanisms responsible for cavitation instabilities were analyzed and described. An original scenario concerning super synchronous instabilities origin was more particularly proposed and discussed.

Further work is now needed to assess the prediction capability of the model. Presently, a detailed study is being performed to improve the applied physical models by taking into account thermodynamic effects. Numerical model aspects are also in progress to succeed 3D unsteady cavitating calculations in inducer real geometries.

\section{ACKNOWLEDGMENTS}

This research was supported by the French space agency CNES (Centre National d'Etudes Spatiales) and the SNECMAMoteurs society. The authors wish also to express their gratitude to NUMECA International for its cooperation to the development of the numerical code. 


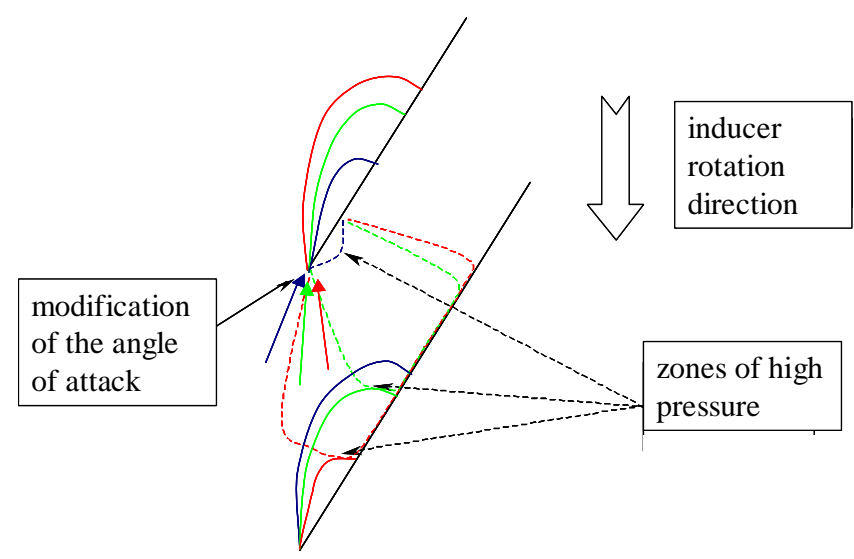

Figure 16: Description of the physical mechanism supposed to be responsible for super synchronous cavitation instability: the rise of the cavity on the upper blade, increase the angle of attack and the pressure near the leading edge, at the pressure side. Then, the cavity facing this leading edge tends to vanish because of the pressure rise.

\section{REFERENCES}

[1] Pouffary B., Fortes-Patella R., Reboud JL. (2003) "Numerical simulation of cavitating flow around a 2D hydrofoil: a barotropic approach", 5th Int. Symp. on Cavitation, Osaka, Japan

[2] Pouffary B. (2004) "Simulation numérique d'écoulements 2d/3d cavitants, stationnaires et instationnaires : analyse spécifique pour les turbomachines", PHD Thesis, Grenoble, France, December 2004 (in French).

[3] Pouffary B., Fortes-Patella R., Reboud J.L. (2005) "Numerical simulation of 3D cavitating flows: analysis of cavitation head drop in turbomachinery", Proceedings of FEDSM2005, June 19-23, 2005, Houston, USA

[4] Hakimi, N. (1997): "Preconditioning methods for time dependent Navier-Stokes equations”, Ph.D.Thesis, Vrije Univ. Brussels.

[5] de Bernardi J., Joussellin F., Von Kaenel A. (1993), "Experimental analysis of instabilities related to cavitation in turbopump inducer", 1st Int. Symp. on Pump Noise and Vibrations, pp. 91-99, Paris, France.

[6] Goirand B., Mertz A., Joussellin F., Rebattet C. (1992), "Experimental investigation of radial loads induced by partial cavitation with liquid hydrogen inducer", 3rd Int. Conf. on Cavitation, ImechE, C453/056, pp. 263-269. Cambridge, U.K.

[7] Joussellin F., Maitre T., Morel P. (1998), "3D Cavity shape in an inducer; experimental investigations and numerical predictions", 3rd Int. Symp. on Cavitation, Grenoble, France.

[8] Kamijo K., Shimura T., Watanabe M. (1977), "An experimental investigation of cavitating inducer instability", ASME Paper 77-WA/FW-14.

[9] Pagnier P, Morel P., Spettel F., Henry C, Champagne J-Y. (1995), "Conception and experimental study of an inducer", In Cav'95 Int. Symp., Deauville, France.

[10] Tsujimoto Y. (2001), "Simple rules for cavitation instabilities in turbomachinery", 4th Int. Symp. on Cavitation, Pasadena, California.
[11] Watanabe, S., Sato, K., Tsujimoto, Y., and Kamijo, K., (1999), "Analysis of rotating cavitation in a finite pitch cascade using a closed cavity model and a Singularity Method", Journal of Fluids Engineering, Vol.121, No.4, pp.834-840.

[12] Horiguchi, H., Watanabe, S., Tsujimoto, Y., and Aoki, M., 2000a, "Theoretical analysis of alternate blade cavitation in inducers", Journal of Fluids Engineering, Vol.122, No.1, pp.156-163.

[13] Joussellin F., Courtot Y., Coutier-Delgosha O., Reboud Jl. (2001), "Cavitating inducer instabilities: experimental analysis and 2D numerical simulation of unsteady flow in blade cascade" Proceedings of the $4^{\text {th }}$ International Symposium on Cavitation, Pasadena, USA.

[14] Fortes Patella R., Coutier-Delgosha, O., Perrin J., Reboud JL (2003), "A numerical model to predict unsteady cavitating flow behaviour in inducer blade cascades", 5th Int. Symp. on Cavitation, Osaka, Japan, and submitted to the Journal of Fluid Engineering.

[15] O. Coutier-delgosha, Y. Courtot, F. Joussellin, JL.. Reboud (2004) "Numerical simulation of the unsteady cavitation behavior of an inducer blade cascade". AIAA journal vol $42 \mathrm{n}^{\circ} 3$, pp 560-56

[16] Spalart PR, Allmaras SR (1992), "A one equation turbulence model for aerodynamic flows", AIAA paper 920439.

[17] Coutier-Delgosha O., Reboud J-L., Delannoy Y. (2003), "Numerical simulation of the unsteady behaviour of cavitating flows", Int. J. for Numerical Meth. In fluids, Vol. 42, pp. 527548.

[18] Lohrberg H., Stoffel B., Fortes-Patella R., CoutierDelgosha, Reboud JL., (2002), "Numerical and experimental investigation on the cavitating flow in a cascade of hydrofoils", Experiments in Fluids, 33/4, pp 578-586.

[19] Coutier-Delgosha O., Fortes-Patella R., Reboud J.L., Hofmann M., Stoffel B. (2003), "Experimental and numerical studies in a centrifugal pump with 2D-curved blades in cavitating conditions", Journal of Fluids Eng. Vol. 125, Issue 6, pp. 970-978

[20] Coutier-DelgoshA O., Fortes-Patella R., Reboud J.L. (2003), "Evaluation of the turbulence model influence on the numerical simulations of unsteady cavitation", Journal of Fluids Engineering, Vol. 25, №1, pp. 38-45, January 2003.

[21] Jameson A. (1991), "Time dependant calculations using multigrid, with application to unsteady flows past airfoils and wings", AIAA Paper 91-1596.

[22] Turkel, E. (1987), "Preconditioning methods for solving the incompressible and low speed compressible equations", Journal of Comp. Phys., vol 72, pp. 277-298.

[23] Choi, D., Merkle, C. L. (1993), "The application of preconditioning in viscous flows", Journal of Comp. Phys., vol 105, pp. 207-223.

[24] Delannoy Y., Kueny J.L. (1990), "Two phase flow approach in unsteady cavitation modelling", Cavitation and Multiphase Flow Forum, ASME-FED vol.98, pp. 153-158. 